\title{
Aprendizagem do conceito de frações frente a situações de aprendizagem sugeridas pela Secretaria de Educação do Estado de São Paulo
}

\author{
Learning of fractions' concept in situations of learning suggested by the \\ Education Department of State of São Paulo
}

Raquel Gomes de

Oliveira

raqueloliveira@,fct.unesp.br

Leonardo Cintra Lopes da Silva

leo.cintra@hotmail.com

\begin{abstract}
Resumo
O objetivo da pesquisa era verificar se no currículo de Matemática proposto pela Secretaria de Educação de São Paulo (SEE) existem referenciais piagetianos considerados determinantes para que aconteça a construção operatória ou significativa do conceito de frações. Para alunos do $6^{\circ}$ ano, que vivenciaram atividades desse currículo, aplicou-se uma prova diagnóstica sobre a relação parte-todo, a associação entre representação pictórica e a linguagem matemática, a equivalência e ordem entre frações e a representação fracionária. Os resultados mostraram que os elementos que compõem o referencial científico piagetiano estão presentes, de forma pontual, no material didático proposto pela SEE, mas a construção operatória do conceito de frações não foi satisfatória. Portanto, é necessário que este material seja reelaborado através de materiais e atividades didáticas que contemplem e possibilitem a articulação dos referenciais piagetianos a fim de que haja essa construção pelos alunos.
\end{abstract}

Palavras Chave: Currículo de matemática, Ensino e aprendizagem, Frações.

\begin{abstract}
The objective of the research was to see if the mathematics curriculum proposed by the Department of Education of São Paulo (SSE) there are Piagetians references considered to determining what must happens in the mathematical construction or significant of the concept of fractions. For the 6th grade students, who experienced these curriculum activities, we applied a diagnostic test on the part-whole relationship, the association between pictorial and mathematical language, the equivalence between fractions and order and fractional representation. The results showed that the elements that make up the Piaget scientific referential are present punctually in the didactical material offered by SSE but the mathematical construction of the concept of fractions was not satisfactory. Therefore, it is necessary that this material must be reworked through materials and learning activities that address and enable the articulation of Piagetian references to this construction by the students.
\end{abstract}

Keywords: Mathematics Curriculum, Teaching and learning, Fractions. 


\section{Introdução}

Esta pesquisa tem como tema motivador a aprendizagem do conceito de frações, com seus diferentes significados e representações.

A relevância deste projeto está na necessidade de investigar o atual currículo de Matemática do Estado de São Paulo e verificar se este considera evidências científicas para a aprendizagem deste conceito.

Resultados do Sistema de Avaliação de Rendimento Escolar do Estado de São Paulo SARESP que mostram o desempenho dos alunos quanto ao conceito de frações, em vários contextos, requisitando, portanto de habilidades diferentes, contribuem para que sejam investigados a natureza do material didático disponibilizado às escolas do Estado de São Paulo e o modo como este material é trabalhado em situações de ensino aprendizagem.

Acredito que uma das principais causas para o surgimento dessas dificuldades de compreensão e significação do conjunto dos números racionais, representados na forma de fracionária, é o modo como em geral como as frações são apresentadas aos alunos.

Ao abordar este conteúdo os professores, na maioria das vezes, iniciam conceituando os números racionais dando exemplos, geralmente numéricos, e, após, já começam a realizar operações introduzindo os algoritmos, sem que o aluno compreenda a quantidade que está sendo representada e utilizada na operação. (PROCHNOW, 2010, p.13).

Análises de resultados e comentários que se encontram no Relatório Pedagógico do SARESP (2010) sobre o ensino e aprendizado do conceito de frações contribuíram para a relevância da pesquisa à medida que apontaram necessidades pedagógicas para o trabalho deste conceito. Necessidades esta que requereram a investigação do material didático utilizado nas aulas de Matemática e também não menos importante sobre a forma como foi trabalhado.

Desse modo, a pesquisa buscou verificar a existência de referenciais científicos propostos por Piaget, Inhelder e Szeminska (1948) para que seja realizada a construção de forma significativa do conceito de frações junto ao material didático para o $6^{\circ}$ ano, disponibilizado pela Secretaria de Educação do Estado de São Paulo (SEE).

De acordo com Piaget, Inhelder e Szeminska (1948), a noção de fração relativa tanto à quantidade contínua (área, comprimento volume) quanto à quantidade discreta (bolinhas, grãos, botões) é construída no nível das operações concretas, e a construção do conceito de fração só se torna possível quando ocorrer uma articulação operatória entre os seguintes 
elementos: existência de uma totalidade divisível, existência de um número determinado de partes; esgotamento da divisão do todo; relação entre o número de partes e o número de cortes; presença da igualização das partes; compreensão de que cada fração pode também ser um todo sujeito a novas divisões e atendimento ao princípio da invariância. Este último elemento está relacionado ao fato de a quantidade contínua dos objetos não variar em função da variação de suas formas, posições e arranjos. Para a construção significativa ou operatória do conceito de frações, é preciso que o aluno tenha a capacidade de compreender que essas modificações resultam de transformações mentalmente reversíveis.

Segundo uma reportagem da revista Escola (2008), o uso do contexto social no estudo de frações permite aos alunos manipular o conteúdo, ao mesmo tempo em que será fonte de novos problemas para eles iniciando a construção de novas relações, mas para isso será necessário promover um salto do intuitivo e informal, aprofundando a análise do conceito, o que irá se suceder ao longo dos anos.

Nesse sentido a pesquisa buscou saber se as situações de aprendizagem propostas no Currículo do Estado de São Paulo se apoiam em referências de aprendizagem para este conceito especificamente evidenciados por Piaget, Inhelder e Szeminska (1948) e Piaget (1975) para a construção operatória do conceito de frações pelos alunos.

\section{Fundamentações teóricas e revisão de pesquisa sobre ensino e aprendizagem de frações}

De acordo com Piaget, Inhelder e Szeminska (1948), a noção de fração quer seja relativa à quantidade contínua quanto ou discreta constrói-se no nível das operações concretas e esta construção do conceito de fração só é possível quando ocorrer uma articulação operatória entre os seguintes elementos: existência de uma totalidade divisível; existência de um número determinado de partes; esgotamento da divisão do todo; relação entre o número de partes e o número de cortes; igualização das partes; compreensão de que cada fração pode também ser um todo sujeito a novas divisões e atendimento ao princípio da invariância.

Este último elemento, princípio da invariância, diz respeito ao fato de a quantidade (contínua ou discreta) dos objetos não variar em função da variação de suas formas, posições, arranjos... É preciso que o aluno tenha a capacidade de compreender que essas modificações resultam de transformações mentalmente reversíveis. Somente tendo esta capacidade é que entenderá que uma parte é o resultado da diferença entre o todo e a(s) outra(s) parte(s) e 
também que a soma de todas as partes é igual a este todo. Quando um aluno age sobre um objeto, pela partição e sobreposição de uma parte (a unidade) sobre as outras, tem a possibilidade de conseguir perceber o todo como um múltiplo da unidade tomada. Para Piaget et al (1948), isto também acontece na construção do conceito de número, quando se trabalha simultaneamente com o encaixe de classes e a seriação das relações não simétricas.

$\mathrm{Na}$ presença do esquema de encaixe e de comparação entre as próprias partes, tanto no contexto discreto como no contínuo o aluno conseguirá obter meios, terços e quartos desejados. Já na ausência deste esquema, um quarto ou a metade da metade provocará dificuldades, tanto no contexto contínuo como no discreto. Conforme assinala Piaget, esta dificuldade não está no contexto trabalhado, mas sim na ausência de um esquema de comparação e de encaixe entre as partes e o todo. Assim, o processo de construção do conceito de frações métricas ou numéricas está vinculado aos problemas das relações entre a ação operatória e a representação perceptual, isto é, entre a abstração reflexionante (a partir da ação) e a abstração empírica (a partir do objeto), colocando a primazia na primeira como elemento ativo ou operatório responsável pela generalização necessária para a construção da ideia de número fracionário.

Oliveira (1996) em seu estudo realizado com crianças da $5^{\mathrm{a}}$ série (atual $6^{\circ}$ ano da Educação Básica) utilizou um pré e um pós-teste sobre frações, dividindo as turmas e trabalhando com uma delas de forma convencional e com a outra usando princípios construtivistas e considerando alguns dos elementos propostos por Piaget, Inhelder e Szeminska (1948), chegando ao resultado que o grupo que trabalhou de forma diferenciada obteve melhores resultados quanto à aprendizagem de frações em relação ao grupo que trabalhou de forma convencional.

Magina e Campos (2008) realizaram um estudo com 70 professores polivalentes e 131 alunos da $3^{\mathrm{a}}$ e $4^{\mathrm{a}}$ séries do ensino Fundamental. Os resultados revelaram que os professores superestimam a capacidade de acerto dos alunos principalmente para os da $4^{\mathrm{a}}$ série. Na análise dos dados, constatou-se que os professores conseguiram identificar e explicar os erros dos alunos, contudo apresentaram estratégias de ensino muito limitadas, estratégias estas limitadas ao uso de desenhos ou material concreto, o que pouco contribui para os alunos superarem a dificuldade na aprendizagem de frações. Estas estratégias têm por objetivo facilitar a comparação perceptual das partes com o todo e das partes entre si, em detrimento do ensino 
das operações de ordem e equivalência, consideradas por Magina e Campos (2008) como invariantes operatórios fundamentais para o aprendizado do conceito de frações. Conclui-se também que não há clareza dos diferentes significados de frações para os professores o que os leva a propor situações de aprendizagem restritas ao ensino do significado e da percepção da relação parte-todo.

Magina, Bezerra e Spinillo (2009) realizaram uma pesquisa sobre frações com 57 crianças entre oito e dez anos, todos de escolas públicas da cidade de São Paulo. Em seu trabalho eles dividiram as crianças em três grupos: Grupo Experimental (GE), Grupo de Controle (GC), ambos formados por crianças da $3^{\mathrm{a}}$ série sem instrução alguma sobre frações, e o Grupo de Referência (GR), este com crianças da $4^{\mathrm{a}}$ série que já receberam alguma instrução sobre frações. Todos os grupos foram submetidos a um pré-teste e depois de oito semanas a um pós-teste. Somente o GE durante oito semanas recebeu uma intervenção na qual os alunos trabalhavam com material concreto e manipulativo, representações gráficas variadas (diagramas, representações icônicas, pictográficas entre outras) e folhas de papel quadriculado. Não se priorizou um único material, ao contrario, mostrou-se que as frações poderiam ser representadas de varias maneiras e que existe uma relação entre todas. Também eram colocadas em evidência as dúvidas dos alunos abrindo espaço para discussões sobre os acertos e erros dos mesmos.

A conclusão aponta que existem três tipos de erros padrões tanto no pré quanto no pós-teste. No erro Tipo-1 as crianças interpretam frações como se fossem números naturais, no erro Tipo-2 a criança interpreta a fração como número natural enquanto vai resolver o problema principalmente com quantidades discretas e no erro Tipo-3 não se reconhecia a necessidade de dividir o todo em partes iguais. Este tipo de erro aparecia quando quantidades contínuas estavam envolvidas. Através do pós-teste concluíram que o GE teve um grande avanço passando de $10,2 \%$ de acertos no pré-teste para $69,8 \%$ enquanto que o GC passou de $12 \%$ para $12,3 \%$ e o GR de $10,7 \%$ para $31,8 \%$. Através disso concluíram que a intervenção teve bons resultados, pois as crianças no pré-teste estavam praticamente no mesmo patamar, e depois da intervenção crianças de $3^{\mathrm{a}}$ série obtiveram resultados mais substanciais, mostrando que a maneira em como se apresenta e trabalha as frações interfere e muito no aprendizado do aluno.

O estudo feito por Junior e Colvara (2010), com 22 estudantes universitários dos quais 12 
eram do curso de licenciatura em Matemática, teve como objetivo analisar como alunos de ensino superior lidavam com conceitos fundamentais da Matemática, neste caso, as frações foram o tema. Para a realização do estudo foi aplicado um questionário individual com 11 questões, sendo 9 abertas e 2 da forma verdadeiro ou falso. Depois que eles respondiam o questionário, o mesmo era lido na presença deles onde era conduzida uma entrevista para conseguir identificar qual o raciocínio e a estratégia usada para resolver os problemas propostos no questionário. Os estudantes foram orientados a construir um mapa conceitual sobre frações.

Os resultados mostraram que $67 \%$ dos alunos entendiam Fração como divisão, $17 \%$ Fração como parte de algo, 8\% Fração como razão e proporção e nenhum no modelo Científico. Nesse estudo, os autores puderam constatar que a maioria dos alunos encontra-se distante do nível conceitual que se espera para eles, isto pode ser constatado em seus modelos mentais, pois foram observadas muitas falhas conceituais, e muitas destas falhas podem ter sido originadas através pelas estratégias de ensino adotadas nos primeiros anos de escolaridade.

Maciel e Câmara (2007) aplicaram uma série de 10 questões sobre frações com crianças da $5^{\text {a }}$ série até alunos do $3^{\circ}$ ano do Ensino Médio. No questionário eles variaram a quantidade (contínua e discreta), a representação (figuras ou linguagem natural) e a significado das frações (operador, parte-todo e quociente). Um dado interessante observado no estudo foi que alunos com menor escolaridade obtiveram melhor desempenho nas questões com quantidades contínuas, e somente depois das $7^{\mathrm{a}}$ série que há um equilíbrio de rendimento entre os sujeitos. Maciel e Câmara (2007) constatam em sua pesquisa que 52\% dos erros cometidos pelos alunos do Ensino Fundamental devem-se ao fato da ideia de fração como quantidade discreta estar fortemente associada ao denominador da fração.

Já para os alunos do Ensino Médio, a tendência é realizar uma operação de soma entre os termos da fração, por exemplo: um quarto de $n$ elementos para eles seria $(1+4)$, essa ideia esteve presente em $49 \%$ dos participantes. Para alunos do $3^{\circ}$ Ciclo quando o numerador não é unitário nas frações discretas, $46 \%$ dos sujeitos realizam a operação de soma entre os termos da fração, independente da quantidade do todo, por exemplo: 2/3 de 17 bolinhas seria 5 . Trinta por cento dos alunos do Ensino Médio tendiam a realizar multiplicação entre os termos da fração, por exemplo: $2 / 3$ de 18 , seria 6 . Na pesquisa eram contempladas as ideias de fração como (relação parte-todo, quociente e operador). A ideia de parte-todo é a mais explorada na 
sala de aula, porém os alunos não obtiveram melhor rendimentos no questionário com o passar dos anos de escolaridade. Em relação à ideia de operador, o rendimento se mostra inalterado, tendo um baixo rendimento em todas as séries. A ideia de quociente tem seu melhor rendimento nos alunos da $5^{\mathrm{a}}$ série, para os demais anos os índices de sucesso se mantiveram constantes. Através da análise de 3 categorias de erro, concluem que os erros encontrados pouco se alteram com o desenvolvimento da vida escolar e constatam que alunos do $3^{\circ}$ ciclo, que trabalham números proporcionais obtiveram melhor desempenho nas questões que contemplavam fração como parte-todo e quociente. Os alunos do $3^{\circ}$ ano que tem aulas de Física e Química que trabalham de forma mais acentuada as frações centesimais se saíram melhor em questões que contemplavam as frações como operadores.

Como visto, o ensino e a aprendizagem do conceito de frações têm se mostrado como pertinente tema de pesquisa em que a variedade de objetivos e metodologias contribuem para o entendimento de que muito temos ainda que avançar em estudos que se qualifiquem como parâmetros para um efetivo processo de ensino e aprendizagem de frações, fundamentado sobretudo, pelo entendimento e apresentação curricular deste conceito.

\section{Objetivo e metodologia da pesquisa}

O objetivo geral da pesquisa era analisar a aprendizagem do conceito de frações por alunos do $6^{\circ}$ ano frente à utilização de situações de aprendizagem propostas pelo atual Currículo de Matemática do Estado de São Paulo e veiculadas nas escolas estaduais por meio do Caderno do Professor e do Caderno do Aluno, volumes 1 e 2. Especificamente os objetivos foram: 1) analisar situações de aprendizagem propostas pelo Currículo do Estado de São Paulo em termos da relação entre ação operatória e representação perceptual; 2) analisar se as situações de aprendizagem propiciaram aos alunos elaboração da relação parte-todo e do conceito de operador tanto em grandezas discretas como contínuas; 3) analisar se as situações de aprendizagem propiciaram a elaboração operatória da associação entre representação geométrica e linguagem matemática e 4) analisar se as situações de aprendizagem propiciaram a elaboração dos conceitos de equivalência e de ordem entre frações.

A pesquisa foi realizada por um aluno do $3^{\circ}$ ano do Curso de Licenciatura em Matemática da FCT-Unesp com 20 alunos do $6^{\circ}$ ano de uma escola pública da cidade de Rancharia-SP. Os dados foram levantados através da descrição e análise do material didático denominado 
Caderno do Aluno volume 1 e 2, onde estavam dispostas as sequências didáticas, além da análise de um caderno de classe de um aluno assíduo a fim de verificar como o material didático havia sido desenvolvido. Ainda para o levantamento de dados, aplicou-se uma prova diagnóstica para todos os alunos da sala para averiguar o desempenho quanto ao conceito de frações voltado para a relação parte-todo, associação entre representação pictórica e a linguagem matemática, equivalência e ordem entre frações e representação fracionária.

\section{Sobre a presença de referenciais piagetianos no material didático da SEE}

Analisando o material disponibilizado pela SEE, buscou-se encontrar tanto no mesmo como em sua utilização quais dos referenciais científicos que conforme Piaget et al (1948) e Piaget (1975) necessitam estar presentes e devem ser cognitivamente articulados pelos alunos para que se tenha a construção operatória do conceito de fração. Estes elementos foram caracterizados como: a existência de uma totalidade divisível; a existência de um número determinado de partes; o esgotamento da divisão do todo; a relação entre o número de partes e o número de cortes; a necessidade de igualização das partes; a compreensão de que uma fração pode também ser um todo sujeito a novas divisões e, por fim, o atendimento ao princípio da invariância. O volume 1 do material disponibilizado pela SEE dá inicio ao conceito de frações através do Tangram. (Figura 1). Nesta atividade conseguimos encontrar a existência de uma totalidade divisível, existência de um número determinado de partes e esgotamento da divisão do todo, onde a atividade também explora o conceito da relação partetodo, e o conceito de equivalência entre frações e a representação geométrica e linguagem matemática nas questões propostas. Outro momento onde aparece algum dos referenciais de Piaget no volumel é no estudo de frações equivalentes onde vemos que uma fração pode ser um todo sujeito a novas divisões, onde mais uma vez aparece o conceito de equivalência entre frações. 
Figura 1: Atividade com o Tangram

Materrítica -5 séné/6 mo-Vohane 1

Junte as sete peças e monte o quadeado maiorcomas fguas do Tangram

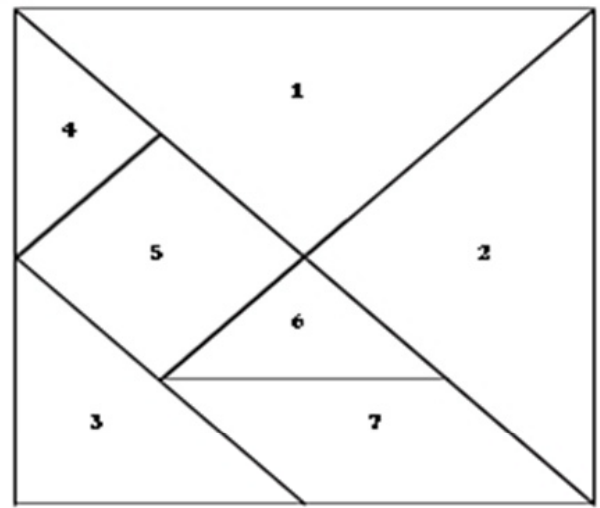

Tivângalos gtandes peças $1 \mathrm{e} 2$

Quadado pequeno perga 5

Triângio médo: peça 3

Pardelogramo peça 7

Thiângilos pequenos: peras 4 e 6

Quadradogtande Tangtamcompleto

2. Tendo camo bre eas peça do Tangtam, tespondà̀s seginites pezgurtas

a) Quantos triârgulos pequenos säo necessários para formarum quadiado pequeno?

b) Umtriângulo pequeno contes ponde a que fraçäo do quadrado pequeno?

Fonte: Caderno do aluno da Secretaria de Educação do Estado de São Paulo

No estudo da comparação de frações onde só não se encontra a noção de que uma fração é um todo sujeito a novas divisões, é trabalhada a noção de ordem entre frações junto com a representação geométrica e linguagem matemática, pois os alunos precisam fazer a representação da fração dada conforme o que se tem na Figura 2. 
Figura 2: Atividade de ordem entre frações.

2. Preencha as figuras de acordo com a fraçáo. Em seguida, compare as fraçóes de cada série usando os sinais de desigualdade: maior que ( $>$ ) ou menor que $(<)$ :

a) Denominador fixo, numeradores diferentes.

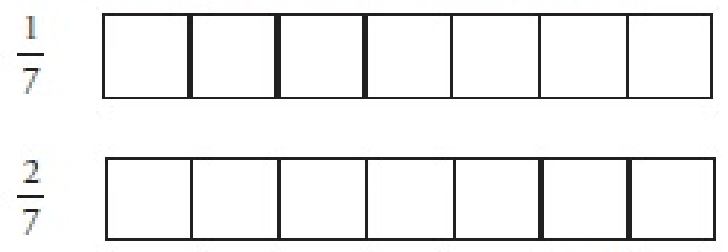

39
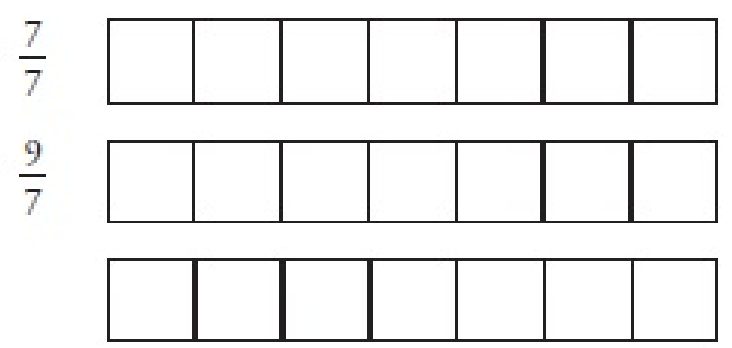

$$
\frac{1}{7}-\frac{2}{7}-\frac{7}{7}-\frac{9}{7}
$$

b) Numerador fixo, denominadores diferentes.

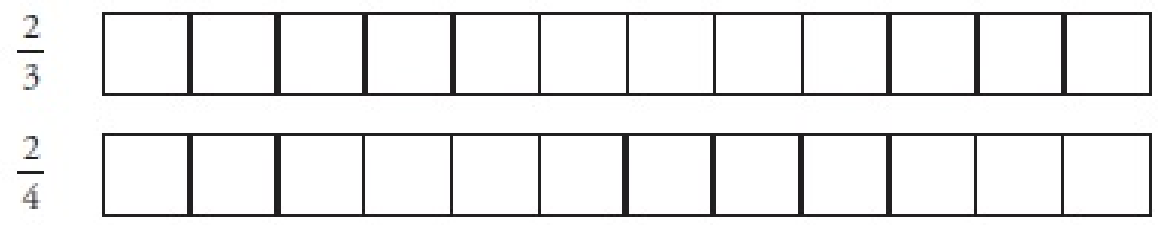

Fonte: Caderno do Aluno da Secretaria de Educação do Estado de São Paulo

O material disponibilizado pela SEE propõe o trabalho pedagógico com a ordem entre frações tanto para o denominador fixo como para o numerador, e no caso do numerador os alunos mais uma vez precisam usar a equivalência entre frações para poder ordená-las de forma correta. Ao estudar fração de um número natural os alunos trabalham as frações com uso de 
operadores, aliado a isto está o princípio de que uma fração é um todo sujeito a novas divisões, onde os alunos podem perceber que: conforme se aplica um operador, o todo vai se dividindo cada vez mais. No último assunto entram em foco as operações com as frações. Neste assunto, os alunos realizam operações de soma e subtração com frações. Para as frações com denominadores diferentes, os alunos têm que usar frações equivalentes onde aparece um dos princípios propostos por Piaget et al (1948): o principio de igualização das partes, porém sem usar nenhum contexto geométrico, todo o exercício é trabalhado de forma aritmética. Coube analisar também que todos estes referenciais propostos neste primeiro volume estão no contexto contínuo.

No volume 2 do Caderno do Aluno disponibilizado pela SEE, percebe-se claramente a ideia de que uma fração é um todo sujeito a novas divisões quando os alunos vão estudar o uso da linguagem mista. Ainda no estudo dos decimais também é trabalhada a representação perceptual na atividade proposta. No entanto, a atividade não contempla nenhum dos princípios trabalhados por Piaget e esta é a única atividade que é trabalhada no contexto discreto.

Para a operação com frações decimais, encontramos a utilização da igualização das partes e mais uma vez a noção de que uma fração é um todo sujeito a novas divisões, junto com os conceitos de equivalência entre frações e ação operatória. A existência de uma totalidade divisível e o esgotamento da divisão do todo aparecem na situação 3, onde podemos perceber a existência da representação perceptual. Ambos os volumes exploram muito o conteúdo de frações de maneira aritmética com muitos cálculos.

Como visto na descrição do material foi possível perceber a existência pontual de referenciais piagetianos para a construção operatória do conceito de frações.

\section{Resultados e análise}

Todas as questões desta análise estão dispostas no apêndice.

Na questão 1, 30\% dos alunos resolveram este tipo de exercício usando as 15 bolinhas de gude como se fosse algo contínuo e não discreto, isso porque desenharam um retângulo e fizeram 15 divisões nele para representar as 15 bolinhas, o que faz pensar que isso se deve aos tipos de exercícios trabalhados no material da SEE que contempla somente o contexto 
contínuo, por exemplo, o primeiro exercício onde os alunos vão construir o conceito de frações já é feito neste contexto, onde os alunos usando uma folha de papel A4 realizam a construção de um Tangram e depois a eles são feitas perguntas sobre qual fração representa uma determinada peça, por exemplo esta questão: "Um triângulo pequeno corresponde a que fração do triângulo grande?". Concluímos que 45\% alunos não têm compreensão operatória sobre a resolução do exercício, porque eles não operam o conceito de fração em termos de comparação e encaixe entre as partes, independentemente se estas são contínuas ou discretas como propôs Piaget et al (1948) e Piaget (1978).

Para a questão 5, percebe-se que os alunos não têm domínio operatório sobre o uso de operadores: 90 \% dos alunos erraram a questão. Uma justificativa para isso é encontrada em Lamon (2006) para o qual um operador é um:

[...] conjunto de instruções para executar um processo. Por exemplo, " $2 / 3$ de" é um operador que instrui você para multiplicar por 2 e dividir por 3. Para aplicar o operador " $2 / 3$ de" realizamos as operações familiares de multiplicação e divisão sucessivamente. [...] o operador $2 / 3$ pode ser visto como uma única operação numa quantidade Q, pode ser visto também como uma multiplicação de Q por 2 seguida da visão do resultado por 3, ou ainda, como uma divisão de Q por 3 seguida da multiplicação do resultado por 2." (LAMON, 2006, p. 151-152).

Baseando-se em Lamon (2006) é possível concluir que, não houve por parte dos alunos a assimilação do uso dessas instruções, realizando assim somente a operação da divisão de 21 por 7, não entendendo como é necessário fazer a multiplicação pelo numerador 3 ou que devem tomar 3 parcelas iguais do resultado da divisão, o que na questão 1 pode ter causado menos erros (70\%) devido ao fato de o numerador ser 1.

A questão 2 teve $90 \%$ de acertos, levando a inferir que isto pode se deber ao fato de ser o modelo de exercício mais trabalhado no Caderno do Aluno da SEE, além de os alunos poderem realizar a contagem da quantidade de quadrados que compunham a figura. Porém na questão 4, o número de acertos (30\%) foi menos da metade da questão 2 (90\%), levando a questionar sobre a causa de tal diferença. Uma possível explicação para essa diferença entre as porcentagens de acertos para questões que tratam do mesmo conceito é dada por Hasemann (1986) que em entrevistas com crianças da $7^{\mathrm{a}}$ série, mostra que é possível ter-se diferentes desempenhos em questões que tratam de um mesmo conceito. Estas diferenças são causadas pelas diferentes representações internas que diferem em noções e conceitos objetivos ao mesmo tempo. 
Para a questão 3, a resposta errada e mais frequente (80\%) em relação a afirmativa " $1 / 10$ é maior que 1/8", sugeriu que os alunos não entendem que a fração é também uma representação da operação de divisão. Logo, quando eles comparam frações, se a fração tiver um numerador igual ao da outra a que tiver maior denominador será menor. De certa forma os alunos ainda estão trabalhando no campo dos números naturais. Bocalon (2008) em seu estudo sobre o Erro na Aprendizagem de Frações, através dos erros mais frequentes, percebeu que os alunos não conseguiram entender e nem representar as frações. O que mostrou que não houve compreensão do conteúdo estudado concluindo que os alunos possuem muita dificuldade em trabalhar com números fracionários e há falta de entendimento sobre o conceito de frações. Para esta questão o ideal seria que os alunos utilizassem o MMC (mínimo múltiplo comum) ou então construíssem uma fração equivalente para assim melhor poder analisar. Porém segundo Oliveira (1996) a construção de uma fração a partir de uma dada anteriormente requer um grau elevado de abstração. Grau este que podemos ver que os alunos ainda não possuem.

O conceito de equivalência entre áreas de uma mesma figura geométrica foi observado na questão 7, que contava com a presença dessas figuras. De acordo com os resultados foi possível entender que a representação das áreas pode ter contribuído com o segundo maior número de acertos dos alunos na prova (40\%). No entanto, o índice de erros de $60 \%$ também pode ser considerado alto. Através deste tipo de resultado podemos perceber que ainda é muito falha a compreensão do conceito de equivalência entre áreas de figuras geométricas. Conforme análise das sequências didáticas sugeridas pelo material da SEE é possível perceber que a equivalência de frações é trabalhada apenas aritméticamente.

A representação das frações próprias e impróprias em contexto contínuo, através de figuras geométricas, foi analisada na questão 6. Analisamos primeiramente as frações próprias. Na tabela 1, os dados remetem exclusivamente à representação feita de maneira correta para o numerador e denominador, com denominador representado em partes iguais. Na tabela 2 estão os dados de representação correta de numerador e denominador sem a igualização das partes. 
Tabela 1: Dados da questão 6 sobre representação correta de fração própria

\begin{tabular}{lccc}
\hline $\begin{array}{c}\text { Figura } \\
\text { Geométrica }\end{array}$ & $\begin{array}{c}\text { Número } \\
\text { de Acertos }\end{array}$ & $\begin{array}{c}\text { Total de itens (figuras) } \\
\text { contabilizando as } 20 \\
\text { provas }\end{array}$ & $\begin{array}{c}\text { Porcentagem de acerto frente ao total } \\
\text { de itens (figuras) }\end{array}$ \\
\hline QUADRADO & 5 & 20 & $25 \%$ \\
CÍRCULO & 17 & 60 & $28 \%$ \\
TRIÂNGULO & 0 & 20 & 0 \\
RETÂNGULO & 8 & 20 & $40 \%$ \\
\hline
\end{tabular}

Tabela 2: Dados da questão 6: representação de fração utilizando partes desiguais (considerando a representação correta do numerador e denominador)

\begin{tabular}{ccccc}
\hline $\begin{array}{c}\text { Figura } \\
\text { Geométrica }\end{array}$ & $\begin{array}{c}\text { Representação } \\
\text { utilizando partes } \\
\text { desiguais }\end{array}$ & $\begin{array}{c}\text { Porcentagem de } \\
\text { acertos frente ao } \\
\text { total de itens } \\
\text { (figuras) }\end{array}$ & Não representa & $\%$ \\
\hline QUADRADO & 11 & $55 \%$ & 4 & $20 \%$ \\
CÍRCULO & 28 & $47 \%$ & 4 & $25 \%$ \\
TRIÂNGULO & 16 & $80 \%$ & 5 & $20 \%$ \\
RETÂNGULO & 7 & $35 \%$ & $25 \%$ \\
\hline
\end{tabular}

A figura que teve maior índice de acerto, conforme a tabela 1, foi o retângulo, podendo ter como causa o fato deste aparecer frequentemente no material didático fornecido pela SEE. $\mathrm{Ou}$ seja, isto pode ter refletido diretamente nos dados da questão, pois foi a figura com maior porcentagem de acertos (40\%). Do mesmo modo, o triângulo é uma figura geométrica bem pouco considerada pelo material da SEE, isto porque os alunos não tinham ideia de como fazer a representação correta da fração que se referia ao triângulo: nenhum aluno acertou a representação fracionária em um triângulo. Na tabela 2, percebe-se a porcentagem de acerto porque se considerou apenas a representação correta do numerador e denominador desconsiderando, portanto a necessidade de igualização das partes nas representações 
realizadas. Esse tipo de constatação também é encontrado em Silva (2005) que afirma que quando o ensino enfatiza somente tarefas que apresentem figuras que permitem somente o uso da técnica de dupla contagem (contar a partes em que o inteiro foi dividido (denominador) e a partes que foram consideradas (numerador)), consequentemente não permite ao aluno desenvolver outras técnicas, o que limitará suas ações na resolução deste tipo de tarefa em que a necessidade de o aluno dividir em partes iguais indica o entendimento ou não do conceito que ele tem de frações. Outro exemplo sobre o tipo de tarefas que oportunizamos aos alunos é sobre fração imprópria, como podemos esperar que um aluno represente corretamente 6/4 sendo que só foram trabalhadas curricularmente frações próprias?

Comparando os dados das tabelas 1 e 2, podemos inferir que os alunos possuem o conceito de frações, mas este ainda necessita ser sistematizado, porque na representação geométrica da fração sabem que numerador é o número de partes tomadas e denominador é o número de partes em que o inteiro foi divido, dado que fizeram esas representações nas figuras. Contudo, a maioria dos alunos não considera a necessidade de divisão em partes iguais.

Esta necessidade de sistematização também pode ser encontrada com as representações nos círculos. Os dados mostraram que para o círculo os alunos tiveram 21,6\% dos acertos nos círculos com denominador múltiplo de dois, enquanto que para denominador não múltiplo de dois a porcentagem de acerto foi de apenas 6,6\%. O mesmo também acontece na tabela 2 na qual para múltiplos de 2, o percentual de acertos foi $28,33 \%$ e para os não múltiplos foi 18,33\%. Logo, é possível considerar que devido ao fato de o denominador ser um múltiplo de dois, ou seja, isto foi um facilitador para que os alunos acertassem ao fazer as divisões na figura. É interessante observar a contradição dos resultados entre o quadrado e o retângulo que são figuras parecidas em sua forma para os alunos. Enquanto o retângulo teve $40 \%$ de acertos o quadrado teve apenas $25 \%$. Na análise das provas um fato observado foi que $45 \%$ dos alunos fizeram a representação de $2 / 3$ igual a da figura dada na questão 4 , onde percebemos que os alunos sabem em quantas partes devem dividir a figura porém não consideram a igualização entre as mesmas. 
Tabela 3: Dados da questão 6 sobre a representação de frações impróprias

\begin{tabular}{|c|c|c|c|c|c|c|}
\hline $\begin{array}{l}\text { Total de itens } \\
\text { (figuras) } \\
\text { contabilizando } \\
\text { as } 20 \text { provas }\end{array}$ & $\begin{array}{c}\text { Representa } \\
\text { Corretamente } \\
\text { fazendo uso } \\
\text { de outro } \\
\text { inteiro }\end{array}$ & $\begin{array}{l}\text { Porcentagem } \\
\text { de acerto } \\
\text { frente ao } \\
\text { total de itens }\end{array}$ & $\begin{array}{c}\text { Representa } \\
\text { erroneamente } \\
\text { (inverte } \\
\text { numerador e } \\
\text { denominador) }\end{array}$ & $\begin{array}{c}\text { Porcentagem } \\
\text { de erro } \\
\text { frente ao } \\
\text { total de itens } \\
\text { (figuras) }\end{array}$ & $\begin{array}{c}\text { Não } \\
\text { representa }\end{array}$ & $\%$ \\
\hline 40 & 7 & $17.5 \%$ & 5 & $12.5 \%$ & 28 & $70 \%$ \\
\hline
\end{tabular}

Os dados mostram que a quantidade de alunos que consegue fazer a representação de frações impróprias, de maneira correta, é pouca $(17,5 \%)$ frente ao número de alunos que não conseguem fazer essa representação $(70 \%)$.

Oliveira (1996) em seu trabalho explica sobre a dificuldade na representação de frações em figuras geométricas. No estudo, constatou-se que os alunos quando trabalham em situações de certa forma desconhecidas para os mesmos, eles procuram de alguma forma representar tal situação e para isso utilizam procedimentos que estariam corretos para outra situação. Segundo Oliveira (1996) é como se a dificuldade da situação permitisse aos alunos uma forma de regressão cognitiva. Assim a ideia de dividir em partes iguais, entendida em outras situações foi deixada de lado.

Silva e Almouloud (2008) fazem a seguinte observação em seu estudo:

Comumente, o ensino utiliza e prioriza o trabalho com a concepção parte-todo
baseado, principalmente, em figuras que representam grandezas contínuas, tais como
segmentos, polígonos e círculos, sendo, por isso, natural o uso dessas figuras para
compreensão das regras operatórias com números fracionários. No entanto, um
primeiro ponto que deve ser considerado é a impossibilidade de o resultado ser
maior que o inteiro, pois, se para a fração $2 / 3$, por exemplo, a criança compreende
que o inteiro foi dividido em três partes, de mesma área ou "iguais", das quais duas
estão sendo consideradas, como explicar a fração $5 / 3$ ? Como obter cinco partes se o
inteiro foi dividido em três? (SILVA E ALMOULOUD, 2008, p.59).

Esta dúvida é o tipo de dúvida que vários alunos apresentaram durante o teste, podemos perceber isso através da porcentagem de erro (70\%), um fato que pode justificar este resultado é o fato do material da SEE possibilitar minimamente o trabalho pedagógico com frações impróprias, sendo que este trabalho só ocorre em um único exercício, que é o da figura 6 , e neste a divisão da figura já está previamente feita. 
Os dados desta pesquisa corroboram com a afirmação de Ciscar e García (1988) na qual "as ideias relativas ao conceito de fração demandam um tempo considerável, em relação ao processo de ensino e aprendizagem", concluindo que a diversidade das estruturas cognitivas e as diferentes interpretações dadas para as frações condicionam tais processos. A caracterização e a identificação dos contextos que tornam significativas as ideias sobre fração estariam ligadas a um conceito maior. Ou seja o conceito global ou total de frações não pode ser adquirido de uma só vez.

\section{Conclusões}

Através dos dados obtidos pela pesquisa e pela análise do material fornecido pela SEE, percebe-se que o material contempla sim alguns elementos piagetianos, dentre os quais estão presentes: existência de uma totalidade divisível; existência de um número determinado de partes; esgotamento da divisão do todo; compreensão de que uma fração é um todo sujeito a novas divisões e necessidade de igualização das partes. Elementos como a relação entre o número de partes e o número de cortes e o princípio da invariância não são trabalhados no material. Estes elementos estão presentes na sequência da SEE de forma pontual, o que não possibilitou aos alunos ter a devida articulação cognitiva ou operatória entre os mesmos.

Os dados também nos mostram que a compreensão dos alunos quanto a conceitos como equivalência entre frações e fração como uma representação da divisão é muito falha.

É possível concluir que isso se deve ao modo como eles são apresentados/trabalhados didaticamente com os alunos. Na maior parte do material da SEE os conceitos relativos ao conceito de fração são trabalhados predominantemente na forma aritmética, tendo muito pouco uso de representações geométricas. Tomemos como exemplo o trabalho com as operações de soma e subtração, em momento algum é inserido este trabalho com contexto geométrico.

O trabalho no contexto discreto também não aparece, o material privilegia em sua maioria o trabalho na forma contínua o que não oportuniza aos alunos terem uma percepção de todas as formas possíveis de se trabalhar com as frações. Com isso, concluir-se que o material fornecido pela SEE contempla alguns elementos de Piaget et al (1948) e Piaget (1975), porém conforme também dados de outros estudos, é necessário que este material seja reelaborado a partir de sua complementação com uso de materiais e atividades didáticas que contemplem e 
possibilitem a articulação dos referenciais piagetianos a fim de que haja a construção operatória do conceito de frações pelos alunos.

\section{Referências}

BOCALON, G. Z. O Erro na Aprendizagem de Frações no Ensino Fundamental: Concepções Docentes. Dissertação (Mestrado em Educação)-PUC/PR. Curitiba, 2008.

CISCAR, S.; GARCÍA, M. V. S. Fracciones. Madri-Espanha: Sintesis, 1988.

MACIEL, A.; CÂMARA, M. Analisando o Rendimento de Alunos das Séries Finais do Ensino Fundamental e do Ensino Médio em Atividades Envolvendo Frações e Ideias Associadas. Bolema, 28, p. 163-177, 2007.

MAGINA, S; BEZERRA, F. B; SPINILLO, A. Como desenvolver a compreensão da criança sobre fração? Uma experiência de ensino. RBEP, 90, 225, p. 411- 43, 2009.

MAGINA, S; CAMPOS, T. A fração na perspectiva do professor e do aluno dos dois primeiros ciclos do ensino fundamental. Bolema, 31, p. 23-40, 2008.

NUNES, T.; BRYANT, P. Crianças fazendo matemática. Porto Alegre: Artes Médicas, 1997.

OLIVEIRA, R. G. Aprendizagem de Frações: Uma Análise Comparativa de Dois Processos Diferentes de Ensino na $5^{a}$ série do $1^{o}$ grau. Dissertação (Mestrado em Educação)UNICAMP/SP. Campinas. 1996.

PIAGET, J. Introduction a la Epistemologia Genética. 1. El Pensamiento Matemático. Buenos Aires: 1975.

.; Inhelder, B. e Szeminska, A. La Partition des Surfaces et la Notion de Fraction. In: La Geómétrie Spontanée de l'Enfant. Paris: Press Universitaires de France, 1948.

PROCHNOW, K. Z. S. Uma Abordagem Diferenciada dos Números Racionais na Forma Fracionária. Monografia (Especialisação em Matemática)-UFRGS/RS. Porto Alegre, 2010.

SÃO PAULO (Estado). Secretaria da Educação. Caderno do Professor: matemática, ensino fundamental. São Paulo, 2012.

SÃO PAULO (Estado). Secretaria da Educação. Caderno do Aluno da Secretaria da Educação do Estado de São Paulo vol -1 e 2. São Paulo, 2009.

SILVA, M. J. F. Investigando Saberes de Professores do Ensino Fundamental com Enfoque em Números Fracionários para a quinta Série. Dissertação (Doutorado em Educação Matemática)-PUC/SP. São Paulo, 2005.

; ALMOUlOUD, S. A. As Operações com Números Racionais e seus Significados a partir da Concepção Parte-todo. Bolema, 31, p. 55-78, 2008. 
VIEIRA JR, N.; COLVARA, L. D. Os Modelos Mentais de Frações: Como universitários lidam com conceitos fundamentais de Matemática? Ciências e Cognição: Núcleo Temático: EDUCAÇÃO, TECNOLOGIA E COGNIÇÃO, 15, 1, p. 137-154, 2010. 


\section{Apêndice}

\section{Avaliação Diagnóstica aplicada para alunos do $6^{\circ}$ ano}

Nome:

série:

1) Arthur perdeu $\frac{1}{3}$ de 15 bolinhas de gude. Pode-se dizer que Arthur perdeu:
a) 12 bolinhas
b) 3 bolinhas
c) 5 bolinhas
d) 4 bolinhas

2) A parte
a) $\frac{5}{10}$
b) $\frac{5}{15}$
c) 5
d) $\frac{10}{5}$

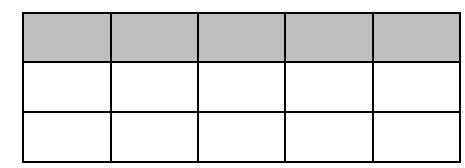

pintada na figura abaixo representa a fração:

3) Quando comparamos as frações $\frac{1}{8}$ e $\frac{1}{10}$, percebemos que:
a) $\frac{1}{10}$ é maior que $\frac{1}{8}$
b) $\frac{1}{10}$ é menor que $\frac{1}{8}$
c) $\frac{1}{10}$ e $\frac{1}{8}$ são equivalentes
d) $\frac{1}{10}$ e $\frac{1}{8}$ não podem ser comparados

4) A parte pintada na figura abaixo representa qual fração desta figura?
a) 1
b) $\frac{1}{4}$
c) $\frac{1}{2}$
d) $\frac{1}{3}$

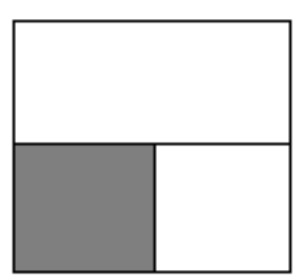

5) João comeu $\frac{3}{7}$ de 21 jabuticabas. Assim, João comeu:
a) 11 jabuticabas.
b) 9 jabuticabas. 
c) 3 jabuticabas.

d) 4 jabuticabas.

6) Para cada figura represente a fração que está abaixo dela:

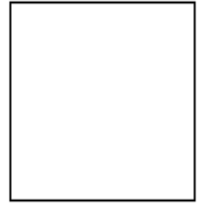

$2 / 3$

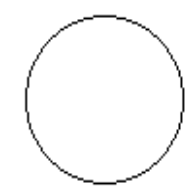

$3 / 5$

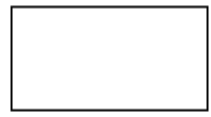

$2 / 8$

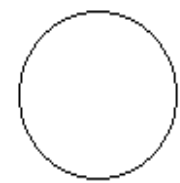

$2 / 4$

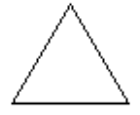

$1 / 3$

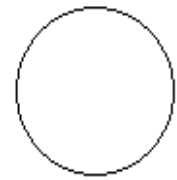

$1 / 6$

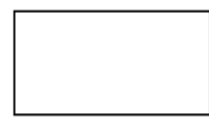

$6 / 5$

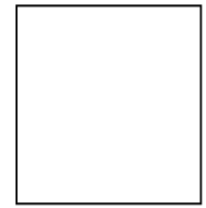

$4 / 3$

7) Ligue a única figura que tem área equivalente à área da figura $X$ :
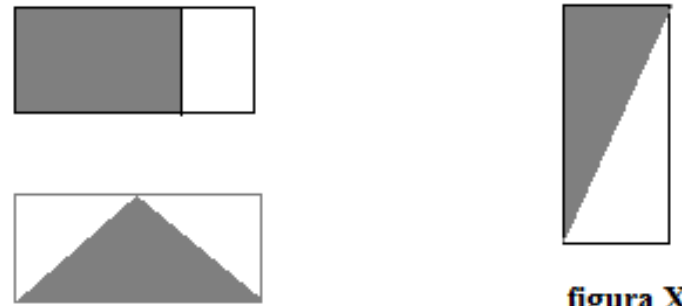

figura $X$
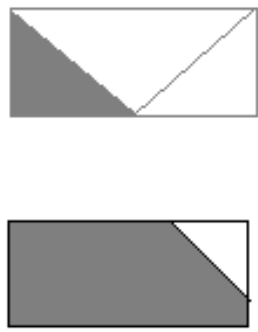